\title{
Effect of using population-specific body mass index cutoff points in the risk assessment of pregnant Asian women for venous thromboembolism
}

\author{
Nau'shil Kaur Randhawa ${ }^{1}$, MBBs, Eng Kien $\underline{\operatorname{Tan}}^{1}$, MBChB, MRCoG, Manali Ashok Sabnis ${ }^{2}$, BSc
}

INTRODUCTION Current international Royal College of Obstetricians and Gynaecologists (RCOG) guidelines list maternal obesity (body mass index $[B M I] \geq 30.0 \mathrm{~kg} / \mathrm{m}^{2}$ ) as a risk factor for venous thromboembolism (VTE). Although the World Health Organization (WHO) has recommended lower BMI cutoff points for Asians when risk stratifying for diseases associated with obesity, this has not been extended to maternal obesity. In the present study, we compared the difference in using Asian-specific BMI cutoff points as opposed to those in international guidelines in determining the population at risk for VTE, as defined by RCOG guidelines.

METHODS All spontaneous deliveries $(n=94)$ and Caesarean sections $(n=41)$ over a three-week period, and instrumental deliveries $(n=15)$ over a two-month period, were reviewed and risk stratified based on Asian-specific, as well as international, BMI cut-off points.

RESULTS For the group that underwent spontaneous vaginal delivery, the percentage of patients at risk for VTE nearly doubled (from $8.5 \%$ to $16.0 \%$ ) with the revised risk stratification, while that of patients who had instrumental delivery had more than a two-fold increase (250\%). In the initial risk stratification of the post-Caesarean patients, none were at high risk of VTE. However, when the lower cut-off points of $27.5 \mathrm{~kg} / \mathrm{m}^{2}$ and $23.0 \mathrm{~kg} / \mathrm{m}^{2}$ were used, one and three patients were respectively identified to be at high risk.

CONCLUSION Further research and consideration regarding the adjustment of international risk stratification guidelines to accommodate population-specific differences are required so that at-risk patients are not missed.

Keywords: ethnicity, pregnancy, puerperium, risk assessment, thromboembolism

\section{INTRODUCTION}

The leading direct cause of maternal death in the United Kingdom, at 1.56/100,000 maternities, is pulmonary embolism. ${ }^{(1)}$ Overall, pulmonary embolism contributes to $11 \%$ of maternal deaths, making it the second most common cause. ${ }^{(1)}$ The relative risk of venous thromboembolism (VTE) is increased by up to six times in pregnancy, ${ }^{(2)}$ and is even higher during the postpartum period. (3) The incidence of VTE in pregnancy and puerperium is $1-2 / 1,000 .^{(2,4-6)}$ Risk assessment to decide on whether or not thromboprophylaxis is still needed, as the risk of VTE, although increased, is still low in pregnancy and puerperium. ${ }^{(7)}$

Obesity, defined by the World Health Organization $(\mathrm{WHO})^{(8)}$ as excessive fat accumulation, has become a global epidemic, contributing to the global incidence of chronic diseases such as type 2 diabetes mellitus, cardiovascular disease, cerebrovascular disease and certain kinds of cancer. As a result of its high prevalence, obesity has become a major contributing factor to the rates of VTE in pregnancy and puerperium. ${ }^{(9)}$ Between 2003 and 2005, out of 33 women who died from pulmonary embolism in the United Kingdom, $12(36 \%)$ were obese. ${ }^{(1)}$ The Royal College of Obstetricians and Gynaecologists (RCOG) guidelines currently list maternal obesity as a risk factor for VTE. ${ }^{(10)}$ Women who have a body mass index $(\mathrm{BMI}) \geq 30.0 \mathrm{~kg} / \mathrm{m}^{2}$ are classified as obese, in line with international classifications proposed by WHO. ${ }^{(11)} \mathrm{BMI}$ is calculated as weight $(\mathrm{kg})$ divided by the square of height $(\mathrm{m})$.

Many studies show that the relationship between BMI and body fat differs with ethnicity. ${ }^{(12-19)}$ Deurenberg-Yap et al studied the relationship between $\mathrm{BMI}$ and the percentage of body fat in the three main racial groups (i.e. Chinese, Malay and Indian) in Singapore. ${ }^{(19)}$ The study showed that body fat percentage was under-predicted by BMI when a Caucasian population-based equation was used. Among the three racial groups studied, Indians were shown to have the highest body fat percentage, and Chinese the lowest, for the same BMI. ${ }^{(19)}$ This is possibly attributed to differences in body-build. The study by Deurenberg-Yap et al found that the BMI cutoff points for obesity would have to be lowered to $27.0 \mathrm{~kg} / \mathrm{m}^{2}$ for Chinese and Malays, and $26.0 \mathrm{~kg} / \mathrm{m}^{2}$ for Indians in order for these races to have the same body fat percentage as Caucasians who have a BMI of $30.0 \mathrm{~kg} / \mathrm{m}^{2}$. $^{(19)}$

The 2002 WHO Expert Consultation on BMI in Asian populations, which reviewed studies and evidence that BMI and body fat percentage differ across populations, recommended that for some Asians, a BMI $\geq 23.0 \mathrm{~kg} / \mathrm{m}^{2}$ reflects a moderate risk for obesity-related diseases, while a

${ }^{1}$ Department of Obstetrics and Gynaecology, National University Hospital, Singapore, ${ }^{2}$ Southampton University, University Road, Southampton, Hampshire, United Kingdom

Correspondence: Dr Nau'shil Kaur Randhawa, Obstetrics and Gynaecology Specialist Trainee, Department of Obstetrics and Gynaecology, National University Hospital, 5 Lower Kent Ridge Road, Singapore 119074.naushil_randhawa@yahoo.com.sg 
BMI $\geq 27.5 \mathrm{~kg} / \mathrm{m}^{2}$ reflects high risk. ${ }^{(2)}$ Therefore, both the Ministry of Health and Health Promotion Board in Singapore have promoted the adoption of these Asian-specific BMI cutoff points in clinical interventions. ${ }^{(20)}$ This, however, has not been extended to maternal care, and current international RCOG guidelines, which define obesity as a BMI $\geq 30.0 \mathrm{~kg} / \mathrm{m}^{2}$, are still being used for risk stratification in many Singapore institutions. Thus, the primary objective of this study was to assess and compare the difference in the number of patients considered to be at risk for VTE (as defined according to RCOG guidelines) when Asian-specific BMI cutoff points are used instead.

\section{METHODS}

The study proposal was reviewed and granted ethics approval by the Domain Specific Review Board. We retrospectively studied the case notes of 94 spontaneous deliveries and 41 Caesarean sections over a three-week period, as well as 15 instrumental deliveries over a two-month period. Telephone and personal interviews were also conducted to identify any risk factors for VTE based on RCOG guidelines. The heights and weights of the patients at booking were used to calculate their BMI, and the patients were risk stratified based on both Asian-specific and international cutoff points.

Based on RCOG guidelines, ${ }^{(10)}$ the 41 post-Caesarean section patients were classified into three main groups: (a) lowrisk patients, for whom early mobilisation was recommended; (b) moderate-risk patients, which included those with $\geq 2$ moderate risk factors; and (c) high-risk patients, which included patients with 1 high risk factor or $>2$ moderate risk factors. Pharmacological thromboprophylaxis was recommended for moderate- and high-risk patients. Moderate risk factors included age $\geq 35$ years at delivery, obesity (defined as BMI $\geq 30.0 \mathrm{~kg} / \mathrm{m}^{2}$ at booking), parity $\geq 4$, labour $\geq 12$ hours, presence of varicose veins, presence of current infection, presence of preeclampsia, immobility $\geq 4$ days prior to delivery, major current medical illness and emergency Caesarean section during labour. High risk factors included major pelvic or abdominal surgery, personal or family history of VTE or thrombophilia, paralysis of lower limb, presence of antiphospholipid antibodies or lupus anticoagulant, and presence of $\geq 3$ moderate risk factors.

The 109 patients who had either spontaneous vaginal or instrumental delivery were classified into two main groups: (a) at-risk patients, for whom the use of pharmacological thromboprophylaxis postpartum was considered; and (b) patients who were not at risk for VTE. According to RCOG guidelines, ${ }^{(10)}$ the risk factors for VTE after spontaneous and instrumental deliveries can be divided into those that are pre-existing and those that are new-onset or transient. Preexisting factors include previous VTE, antithrombin deficiency, protein $\mathrm{C}$ deficiency, protein $\mathrm{S}$ deficiency, factor $\mathrm{V}$ Leiden thrombophilia, prothrombin gene variant, antiphospholipid
Table I. Number of patients at risk for venous thromboembolism according to BMI cutoff points.

\begin{tabular}{lccc}
\hline Parameter & \multicolumn{3}{c}{ BMI cutoff $\mathbf{( k g / \mathbf { m } ^ { 2 } )}$} \\
\cline { 2 - 4 } & $\mathbf{3 0 . 0}$ & $\mathbf{2 7 . 5}$ & $\mathbf{2 3 . 0}$ \\
\hline SVD $(\mathbf{n}=\mathbf{9 4})$ & $8(8.5)$ & $15(16.0)$ & $24(25.5)$ \\
At risk & & & \\
LSCS $\mathbf{( n = 4 1 )}$ & $12(29.3)$ & $14(34.1)$ & $18(43.9)$ \\
$\quad$ Moderate risk & $0(0)$ & $1(2.4)$ & $3(7.3)$ \\
High risk & & & \\
IVD ( $\mathbf{n}=\mathbf{1 5})$ & $4(26.7)$ & $6(40.0)$ & $10(66.7)$ \\
$\quad$ At risk & &
\end{tabular}

Data is presented as no. (\%).

IVD: instrumental vaginal delivery; LSCS: lower segment Caesarean section; SVD: spontaneous vaginal delivery

syndrome, presence of lupus anticoagulant, presence of anticardiolipin antibodies, age $\geq 35$ years at delivery, obese (defined as a BMI $\geq 30.0 \mathrm{~kg} / \mathrm{m}^{2}$ at booking), parity $\geq 4$, presence of gross varicose veins, paraplegia, sickle cell disease, inflammatory diseases (e.g. inflammatory bowel disease), medical disorders (e.g. nephritic syndrome and certain cardiac diseases) and myeloproliferative disease (e.g. essential thrombocythaemia and polycythaemia vera). New-onset or transient factors include surgical procedure in pregnancy (e.g. evacuation of products of conception, removal of placenta or postpartum sterilisation), hyperemesis, dehydration, ovarian hyperstimulation syndrome, severe infection (e.g. pyelonephritis), immobility $\geq 4$ days prior to delivery, presence of preeclampsia, excessive blood loss $(>1 \mathrm{~L}$ ), long-haul travel, labour $\geq 12$ hours, instrumental delivery and immobility after delivery. Women who had any two of the above risk factors (whether pre-existing or newonset, or previous VTE with or without thrombophilia), as well as women who had thrombophilia without previous VTE were considered to be at risk. This was in line with the latest RCOG guidelines. ${ }^{(10)}$

The patients were then risk stratified using the BMI cutoff points of $27.5 \mathrm{~kg} / \mathrm{m}^{2}$ and $23.0 \mathrm{~kg} / \mathrm{m}^{2}$, instead of $30.0 \mathrm{~kg} / \mathrm{m}^{2}$, to assess the difference in the prevalence of the at-risk population.

\section{RESULTS}

The results of the present study are summarised in Table I. When a BMI cutoff point of $30.0 \mathrm{~kg} / \mathrm{m}^{2}$ was used to define obesity, $8(8.5 \%)$ of the 94 patients who had spontaneous vaginal delivery were considered to be at risk, while 12 (29.3\%) who underwent Caesarean section were classified as moderate risk. None of the patients who underwent Caesarean section was considered to be at high risk. Of the 15 patients who had instrumental delivery, the use of a BMI cutoff point of $30.0 \mathrm{~kg} / \mathrm{m}^{2}$ resulted in $4(26.7 \%)$ patients being categorised as at risk. Patients considered to be at risk and high risk required pharmacological venous thromboprophylaxis.

Risk stratification performed for the same patients using the Asian-specific BMI cutoff point of $27.5 \mathrm{~kg} / \mathrm{m}^{2}$ for high 
risk for obesity-related diseases gave the following results: $15(16.0 \%)$ patients who had spontaneous delivery were classified as at risk; 14 (34.1\%) and 1 (2.4\%) patients who had Caesarean section were respectively classified as moderate risk and high risk; and 6 (40.0\%) patients who had instrumental delivery were classified as being at risk. When the Asianspecific BMI cutoff point of $23.0 \mathrm{~kg} / \mathrm{m}^{2}$ for moderate risk for obesity-related diseases was used, the following results were obtained: $24(25.5 \%)$ patients who had spontaneous delivery were found to be at risk; 18 (43.9\%) and 3 (7.3\%) patients who had Caesarean section were respectively considered to be at moderate risk and high risk; and 10 (66.7\%) patients who had instrumental delivery were found to be at risk.

\section{DISCUSSION}

Of the 94 patients who underwent spontaneous vaginal delivery, 7 (7.4\%) patients would have been missed, and thus not received pharmacological thromboprophylaxis, if the international BMI cutoff point of $30 \mathrm{~kg} / \mathrm{m}^{2}$ was used instead of the Asian-specific BMI cutoff point of $27.5 \mathrm{~kg} / \mathrm{m}^{2}$. The percentage of patients deemed to be at risk nearly doubled (from $8.5 \%$ to $16.0 \%$ ) with the revised risk stratification. In the case of the 15 patients who underwent instrumental delivery, $2(13.3 \%)$ patients who were found to be at risk using a BMI cutoff of $27.5 \mathrm{~kg} / \mathrm{m}^{2}$ were missed out in the initial risk stratification, which used a BMI cutoff point of $30.0 \mathrm{~kg} / \mathrm{m}^{2}$. Furthermore, when a BMI cutoff point of $23.0 \mathrm{~kg} / \mathrm{m}^{2}$ was used, the number of at-risk patients had more than a two-fold increase $(250 \%)$, with six at-risk patients missed out in the initial risk stratification. In the initial risk stratification of the postCaesarean patients, there were no patients deemed to be at high risk for VTE, which meant that none of the patients were deemed to require thromboembolism-deterrent (TED) stockings and low-molecular-weight (LMW) heparin. However, when BMI cutoff points of $27.5 \mathrm{~kg} / \mathrm{m}^{2}$ and $23.0 \mathrm{~kg} / \mathrm{m}^{2}$ were used to stratify the patients, $1(2.4 \%)$ and $3(7.3 \%)$ patients were respectively identified to be at high risk.

In the present study, none of the patients developed VTE. The study cohort included both private patients managed by private obstetricians and subsidised patients managed by the resident in a call team. At the time of the study, the Department of Obstetrics and Gynaecology at the National University Hospital, Singapore, did not have hospital-specific guidelines on risk stratification of patients for VTE or the administration of venous thromboprophylaxis during pregnancy and puerperium. Instead, the delivery suite team adhered to the international RCOG guidelines, and the respective consultants-in-charge made decisions on the management of subsidised cases independently. As the purpose of this study is not that of an audit, the percentages of at-risk patients (according to the various risk stratifications) given TED stockings and postpartum LMW heparin were not presented. The single high-risk post-Caesarean patient who was managed by one of the study team members had been given LMW heparin postpartum.

The present study shows that when international RCOG guidelines for risk stratification are used to decide whether pharmacological thromboprophylaxis is required, a significant proportion of at-risk patients were overlooked. In view of the revision of the BMI cutoff points for Singapore ${ }^{(20)}$ (based on the recommendations of the WHO Expert Consultation), the importance of obesity as a risk factor for VTE, ${ }^{(1,9-10)}$ and the $3.5 \%$ fatality rate of pulmonary embolism, ${ }^{(21)}$ the results of this study highlight the need to draw up population-specific guidelines for identifying Asian patients at risk for VTE and who require LMW heparin, lest these patients be deemed as low risk and not requiring prophylaxis. It is also not sufficient to extrapolate BMI cutoff points for a non-pregnant population to a pregnant population, as it has not been proven whether there will be a similar increase in risk for VTE. Research must, therefore, be directed toward identifying the BMI cutoff point for pregnant Asians that corresponds to a similar VTE risk as that in pregnant Caucasians with a BMI of $30 \mathrm{~kg} / \mathrm{m}^{2}$.

In conclusion, the present study shows that a significant proportion of at-risk patients may be missed if international RCOG guidelines are applied to pregnant Asian populations. Since a lower BMI cutoff point in Asians has been shown to be necessary for other interventions in the non-pregnant population, a lower cutoff may similarly apply to the risk stratification of VTE in the pregnant population. Since it is not known whether the Asian-specific BMI cutoff points of the non-pregnant population can be accurately applied to the risk stratification of VTE in pregnant Asian women, further research is warranted.

\section{REFERENCES}

1. Lewis G, ed. The Confidential Enquiry into Maternal and Child Health $(\mathrm{CEMACH})$. Saving Mothers' Lives: Reviewing maternal deaths to make motherhood safer - 2003-2005. The Seventh Report on Confidential Enquiries into Maternal Deaths in the United Kingdom. London: $\mathrm{CEMACH}$, 2007.

2. Heit JA, Kobbervig CE, James $\mathrm{AH}$, et al. Trends in the incidence of venous thromboembolism during pregnancy or postpartum: a 30-year populationbased study. Ann Intern Med 2005; 143:697-706.

3. Pomp ER, Lenselink AM, Rosendaal FR, Doggen CJ. Pregnancy, the postpartum period and prothrombotic defects: risk of venous thrombosis in the MEGA study. J Thromb Haemost 2008; 6:632-7.

4. Jacobsen AF, Skjeldestad FE, Sandset PM. Ante- and postnatal risk factors of venous thrombosis: a hospital-based case-control study. J Thromb Haemost 2008; 6:905-12.

5. James $\mathrm{AH}$. Prevention and management of venous thromboembolism in pregnancy. Am J Med 2007; 120 (10 suppl 2):S26-34.

6. Lindqvist $P$, Dahlback $B$, Marsal $K$. Thrombotic risk during pregnancy: a population study. Obstet Gynecol 1999; 94:595-9.

7. Bauersachs RM, Dudenhausen J, Faridi A, et al. Risk stratification and heparin prophylaxis to prevent venous thromboembolism in pregnant women. Thromb Haemost 2007; 98:1237-45.

8. World Health Organisation. Obesity and overweight: Fact sheet No 311, 2006 [online]. Available at: www.who.int/mediacentre/factsheets/fs311/. Accessed May 15, 2012.

9. Marik PE, Plante LA. Venous thromboembolic disease and pregnancy. N Eng J Med 2008; 359:2025-33.

10. Royal College of Obstetricians and Gynaecologists (RCOG). Green-top 
Guideline No 37a: Reducing the risk of thrombosis and embolism during pregnancy and the puerperium. London: Royal College of Obstetricians and Gynaecologists (RCOG), 2009.

11. WHO Expert Consultation. Appropriate body-mass index for Asian populations and its implications for policy and intervention strategies. Lancet 2004; 363:157-63.

12. Deurenberg P, Yap M, van Staveren WA. Body mass index and percent body fat: a meta analysis among different ethnic groups. Int J Obes Relat Metab Disord 1998; 22:1164-71.

13. Gallagher D, Visser, $M$, Sepulveda D, et al. How useful is body mass index for comparison of body fatness across age, sex, and ethnic groups? Am J Epidemiol 1996; 143:228-39.

14. Gurrici S, Hartriyanti Y, Hautvast JG, Deurenberg P. Relationship between body fat and body mass index: differences between Indonesians and Dutch Caucasians. Eur J Clin Nutr 1998; 52:779-83.

15. He M, Tan KC, Li ET, Kung AW. Body fat determination by dual energy X-ray absorptiometry and its relation to body mass index and waist circumference in Hong Kong Chinese. Int J Obes Relat Metab Disord $2001 ; 25: 748-52$.

16. Norgan NG. Population differences in body composition in relation to the body mass index. Eur J Clin Nutr 1994; 48 suppl 3:S10-25; discussion S26-7.

17. Swinburn BA, Ley SI, Carmichael HE, Plank LD. Body size and composition in Polynesians. Int J Obes Relat Metab Disord 1999; 23:1178-83.

18. Wang J, Thornton JC, Russel M, et al. Asians have lower body mass index (BMI) but higher percent body fat than do whites: comparisons of anthropometric measurements. Am J Clin Nutr 1994; 60:23-8.

19. Deurenberg-Yap M, Schmidt G, van Staveren WA and Deurenberg P. The paradox of low body mass index and high body fat percentage among Chinese, Malays and Indians in Singapore. Int J Obes Relat Metab Disord 2000; 24:1011-7.

20. Health Promotion Board Singapore. Revision of Body Mass Index (BMI) cut-offs in Singapore, 2005 [online]. Available at: www.hpb.gov.sg Accessed May 15, 2012.

21. James AH, Tapson VF, Goldhaber SZ. Thrombosis during pregnancy and the postpartum period. Am J Obstet Gynecol 2005; 193:216-9.

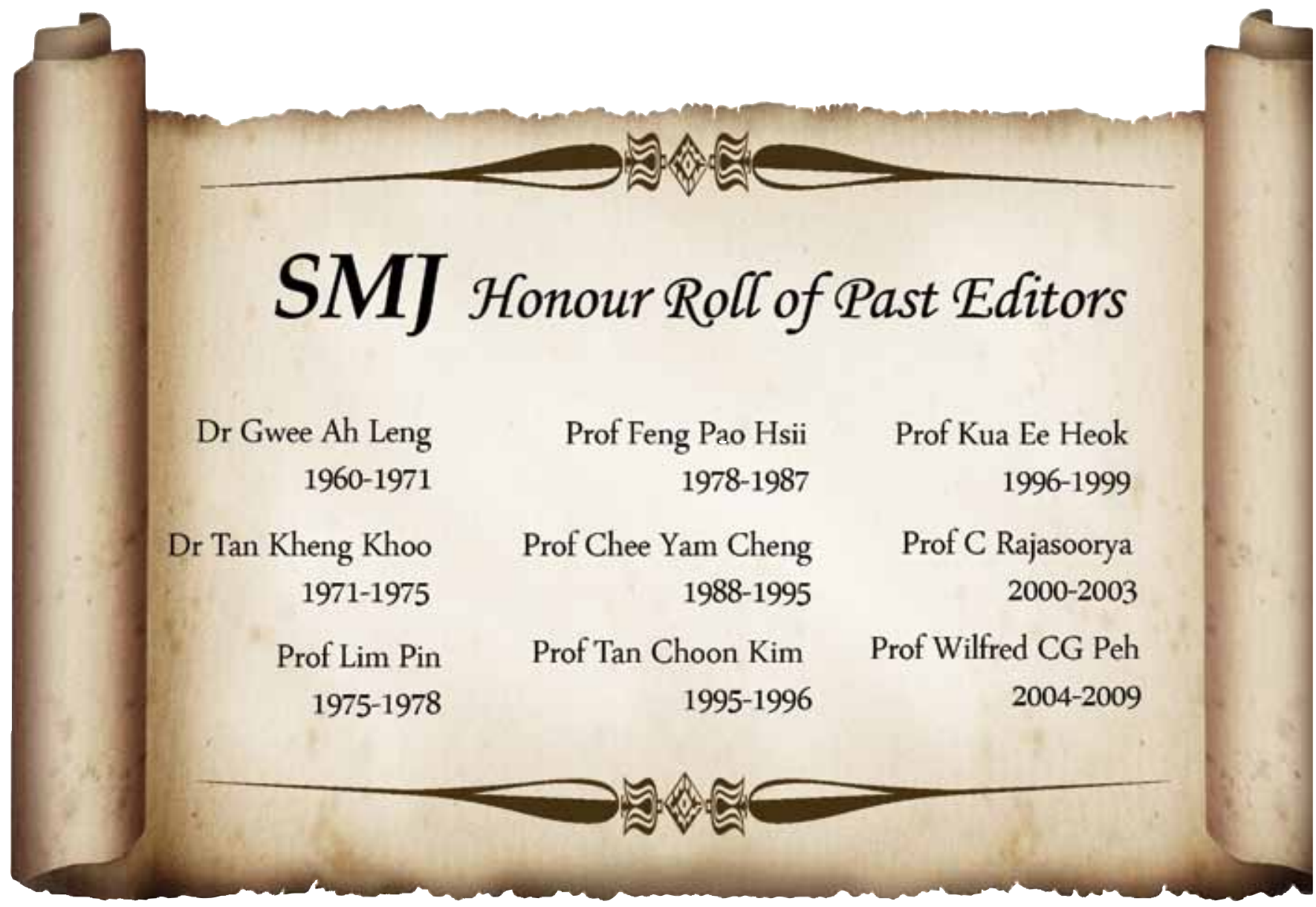

